\title{
The Effects Of Cultural Diversity In The Workplace
}

\author{
Gillian Coote Martin, South Florida College of Arts Science \& Technology, USA
}

\begin{abstract}
Cultural diversity in the workplace has grown as a trend over the passage of time with the increase of globalization in the world. One positive effect is that employees belonging to different cultures usually have different ways of thinking and can thus analyze a matter at hand from a variety of perspectives. This is hard to achieve when employees belonging to the same culture are asked to analyze the same matter.
\end{abstract}

Keywords: Effects; Workplace; Cultural Diversity

\section{INTRODUCTION}

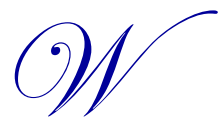

ith the increase of globalization in the world, cultural diversity in the workplace has grown as a trend. "Cultural diversity is when differences in race, ethnicity, language, nationality, religion, and sexual orientation are represented within a community" (Amadeo, 2013). Although the media and contemporary literature embark upon the benefits of cultural diversity in the workplace, citing enhancements to employees' competence and creativity, this recognition does not reflect, in actual practice, as strongly as in theory (Al-Jenaibi, 2011, p. 49). Cultural diversity can affect the workplace in numerous ways. Negative effects can include miscommunication, creation of barriers, and dysfunctional adaptation behaviors. Positive effects can include building a sound knowledge base with in-house talent, which can make for smoother integration of the organization into foreign cultures.

One negative effect of cultural diversity in the workplace is the increased tendency of organizational personnel to indulge in interpersonal conflicts. Culturally diverse workers have different opinions, thoughts, beliefs, norms, customs, values, trends, and traditions. "The analogy of an iceberg comes to mind in the face of these potentially endless dimensions; the obvious characteristics of race, ethnicity, gender, age, and disability relate to the small, visible portion of the iceberg and are the basis of much anti-discrimination legislation around the world" (Białostocka, 2010, p. 6). Not so obvious dimensions, such as culture, religion, and politics, only show up with the passage of time. The core of individual identity constitutes the tertiary dimensions and exists deep beneath the surface. These deeply buried qualities offer the actual essence of diversity. "An individual's spirituality is personal and although effects of their spirituality may be seen at the surface level, the source is still a deep-level artifact" (Moore, n.d., p. 83).

When culturally diverse workers are placed in a group to achieve a goal with mutual effort and collaboration, these differences of opinions and other variables can hinder the development of unity. Harrison, Price, and Bell (1998) assert that the effect of deep-level similarity on group cohesion is positive, while that of deep-level dissimilarity on group cohesion is negative. Workers may have reasons to indulge in conflict with one another that may or may not be related to work at all. For example, a South African and an Indian employee might argue with each other over a cricket match lost by India to South Africa. Likewise, workers may have historical and regional reasons to conflict with each other. For example, a Japanese employee and an American employee might disagree over the Battle of Pearl Harbor. Reasons can vary from very serious to trivial. Whatever the cause, the interpersonal conflict results in lost productivity and development of negative emotions among employees, which can be detrimental to the organization. 
A positive effect of cultural diversity in the workplace is that employees belonging to different cultures usually have different ways of thinking and can thus analyze a matter at hand from a variety of perspectives. This is hard to achieve when employees belonging to the same culture are asked to analyze the same matter. Employees coming from different cultures have different experiences, which can be beneficial by providing the organization with a sound and vast knowledge base. Al-Jenaibi (2011) studied the impact and scope of cultural diversity in organizations in the UAE. The study showed most of the workers agreed that group work with culturally diverse people helps "to overcome cultural differences through shared experiences when working within a team" (AlJenaibi, 2011, p. 71).

Another positive effect of cultural diversity in the workplace is the increased tendency of organizational personnel to overcome culture shock as the business expands in other countries and becomes international. This is a very important benefit derived from cultural diversity of the employees because many modern companies have global expansion on their corporate agendas. With expansion into other countries comes a range of obstacles including, but not limited to, gathering information about local customs and laws in the foreign country, assessing risk, and designing strategies to overcome those risks. When an organization has a culturally diverse workforce, it can use the information and knowledge of the individual workers to achieve these objectives and overcome the aforementioned obstacles. For example, an American company trying to expand its business in India can draw information about the Indian federal and provincial laws that apply to the business, insurances required, and applicable tax regulations.

Another way the knowledge of culturally diverse workers can be useful for the organization is the tendency of the workers to inform the concerned employees or managers about the culture of their respective countries. This helps when they work as expatriates in a foreign country; they have sufficient information about the culture of the foreign country to avoid, or at least minimize, the culture shock. Normally, organizations that do not have a culturally diverse workforce have to incur expenses of getting their workers informed about the culture and work procedures of the foreign countries. Investments might include hiring trainers from foreign countries, purchasing documentaries about foreign cultures to show to employees or distributing books, journals, and pamphlets to increase their knowledge about foreign cultures. All of these measures not only take a lot of time to be arranged, but also cost the company substantial amounts. With a culturally diverse workforce, this time, cost, and energy can be saved as workers in-house serve as trainers and practitioners. Thus, the process of integration of such an organization into a foreign country becomes smoother.

Similarly, cultural diversity of the workforce helps an organization shift its business from the brick-andmortar office to the online marketplace. Diversity helps in the expansion of an organization's perspective, approach, strategic tactics, launch of a new product, development of a marketing plan, creation of a new idea, design of a new operation, and assessment of emerging trends (Adler, 2002). Adler (2002) identified five fundamental strategies for the management of cultural diversity in the workplace; namely, cultural dominance, cultural avoidance, cultural compromise, cultural synergy, and cultural accommodation. Of these, the most desirable strategy is of cultural synergy, which is acquired through placing value in other cultures without giving up self culture (Kamal and Ferdousi, 2009, p. 161).

\section{CONCLUSION}

The impacts of cultural diversity in the workplace can be both favorable and unfavorable. Some negative effects include dysfunctional conflicts, lost productivity, and difficulty to achieve harmony in group settings. Positive effects include a strong knowledge base created by a variety of cultural experiences, an in-house resource of cultural trainers and informers, and a greater tendency to expand the business in foreign cultures. For the most part, the effects of cultural diversity in the workplace depend upon how well they are being managed by the organizational leaders. With proper strategic planning, top management can enhance the positive effects and reduce the negative effects of cultural diversity in the workplace. 


\section{AUTHOR INFORMATION}

Dr. Gillian Martin has a Doctor of Business Administration degree with an emphasis in Marketing, a Master of Management and a Bachelor of Science in Business Management in Marketing.

Email: gilliancootemartin@gmail.com.

\section{REFERENCES}

1. Adler, N. J. (2002). International Dimensions of Organizational Behaviour, $4^{\text {th }}$ Edition, McGill University, South -Western, Thomson Learning, pp.105-131.

2. Al-Jenaibi, B. (2011). The scope and impact of workplace diversity in the United Arab Emirates an initial study. Journal for Communication and Culture. 1(2), 49-81.

3. Amadeo, K. (2013). Cultural Diversity. Retrieved from http://useconomy.about.com/od/suppl1/g/CulturalDiversity.htm.

4. Białostocka, P. (2010). Cultural Diversity in Organisational Theory and Practice. Journal of Intercultural Management. 2(2), 5-15.

5. Harrison, D., Price, K., \& Bell, M. (1998). Beyond Relational Demography: Time and the Effects of Surface and Deep-Level Diversity on Work Group Cohesion. Academy of Management Journal. 41(1), 96107.

6. Kamal, Y. \& Ferdousi, M. M. (2009). Managing Diversity at Workplace: A Case Study of hp. ASA University Review. 3(2), 157-170.

7. Moore, T. W. (n.d.). Individual Differences and Workplace Spirituality: The Homogenization of the Corporate Culture. Journal of Management and Marketing Research. pp. 79-93. 
NOTES 